Article

\title{
Simultaneous Determination of Twenty Mycotoxins in the Korean Soybean Paste Doenjang by LC-MS/MS with Immunoaffinity Cleanup
}

\author{
So Young Woo, So Young Ryu, Fei Tian, Sang Yoo Lee, Su Been Park and Hyang Sook Chun * \\ Advanced Food Safety Research Group, BK21 Plus, School of Food Science and Technology, Chung-Ang \\ University, Anseong 17546, Korea; mochalatte9@naver.com (S.Y.W.); kfbthdud123@gmail.com (S.Y.R.); \\ tianfei_real@163.com (F.T.); dm3822@naver.com (S.Y.L.); sirius6100@naver.com (S.B.P.) \\ * Correspondence: hschun@cau.ac.kr; Tel.: +82-31-6703290; Fax: +82-31-6753108
}

Received: 17 September 2019; Accepted: 9 October 2019; Published: 12 October 2019

\begin{abstract}
Doenjang, a Korean fermented soybean paste, is vulnerable to contamination by mycotoxins because it is directly exposed to environmental microbiota during fermentation. A method that simultaneously determines 20 mycotoxins in doenjang, including aflatoxins (AFs), ochratoxin A (OTA), zearalenone (ZEN), and fumonisins (FBs) with an immunoaffinity column cleanup was optimized and validated in doenjang using LC-MS/MS. The method showed good performance in the analysis of 20 mycotoxins in doenjang with good linearity $\left(R^{2}>0.999\right)$, intra- and inter-day precision $(<16 \%)$, recovery $(72-112 \%)$, matrix effect $(87-104 \%)$, and measurement uncertainty $(<42 \%)$. The validated method was applied to investigate mycotoxin contamination levels in commercial and homemade doenjang. The mycotoxins that frequently contaminated doenjang were AFs, OTA, ZEN, and FBs and the average contamination level and number of co-occurring mycotoxins in homemade doenjang were higher than those in commercially produced doenjang.
\end{abstract}

Keywords: mycotoxins; doenjang; simultaneous determination

Key Contribution: A method for the simultaneous determination of 20 mycotoxins with immunoaffinity cleanup by high-performance liquid chromatography-tandem mass spectrometry was developed and validated. This method can be applied to the investigation of the co-occurrence of multiple mycotoxins in fermented soybean foods, including doenjang.

\section{Introduction}

Mycotoxins, produced mainly by the genera Aspergillus, Penicillium, Fusarium, Claviceps, and Alternaria [1], are unintentional contaminants of agricultural products and food; they cause hepatotoxicity, kidney toxicity, reproductive toxicity, and economic loss [2]. Therefore, most countries regulate the levels of the following mycotoxins in food and feeds: aflatoxin B1 (AFB1), aflatoxin B2 (AFB2), aflatoxin G1 (AFG1), aflatoxin G2 (AFG2), aflatoxin M1 (AFM1), ochratoxin A (OTA), zearalenone (ZEN), T-2 toxin, HT-2 toxin, deoxynivalenol (DON), fumonisin B1 (FB1), fumonisin B2 (FB2), and fumonisin B3 (FB3).

Doenjang, a fermented soybean paste produced in Korea, is a highly nutritious protein source with a high storage stability. During fermentation, the microbiota present in the surrounding environment naturally inoculate the paste and participate in its fermentation. However, simultaneously, this process is vulnerable to contamination by mycotoxigenic fungi that produce aflatoxins (AFs), such as Aspergillus flavus.

The main challenges in accurately determining AF levels in doenjang are matrix effects, such as adsorption and interference, and low AF recoveries. Doenjang contains large quantities of salt (7-23\%), 
high levels of protein and brown pigments, and molecular fermentation by-products. These matrix components have the potential to interfere with the analysis of AFs [3]. Studies to determine mycotoxin levels in doenjang have mainly been conducted to detect AFs. However, to date, very few studies have focused on other mycotoxin contaminants in doenjang, including OTA.

Most methods used for the extraction and purification of mycotoxins in doenjang are solid-phase extractions using an immunoaffinity column (IAC) cleanup. For the quantification of trace levels of mycotoxin in soybean paste matrix, analysis without the clean-up process or using solid phase extraction (SPE) that was packed with general C18 or ion pair materials resulted in insufficient removal of salts and other polar components in the matrix [4]. Analyses of mycotoxins in doenjang, particularly AFs, are typically conducted using high-performance liquid chromatography coupled with fluorescence detection (HPLC-FLD). However, because reverse-phase eluents quench the fluorescence of AFB1 and AFG1 [5], chemical derivatization is frequently required to detect these analytes. Pre-column or post-column derivatization is thus performed with a suitable fluorophore to improve detectability. In addition, the AFs in doenjang have been analyzed by ELISA and LC-MS/MS [4,6-10]. Although HPLC-FLD is more affordable and easier to maintain than LC-MS/MS, LC-MS/MS analysis is more sensitive and suitable for simultaneous determination because it can analyze the mycotoxins lacking fluorophore groups, such as trichothecenes. To the best of the authors' knowledge, there are no reported studies on the simultaneous determination of multiple mycotoxins in doenjang.

Currently, the risk management of mycotoxins in food is assessed using a single mycotoxin [11]. There are, however, various mycotoxins that may contaminate food simultaneously; humans are therefore exposed to the synergistic effect of multiple mycotoxins [12-14]. Thus, it is important to establish an accurate and reliable analytical method for the simultaneous determination of multiple mycotoxins. HPLC-MS has frequently been used to simultaneously determine various mycotoxins in food, particularly by LC coupled with triple quadrupole (QqQ)-MS using electrospray ionization (ESI) mode. QqQ-MS operating in multiple-reaction monitoring mode (also called selective reaction monitoring, SRM mode) provides a more sensitive analysis of targeted or known mycotoxins when using one precursor ion and a few product ions for each analyte compared with full spectral data $[15,16]$. Furthermore, QqQ-MS analysis can reduce dwell times, with faster data collection, without reducing the signal-to-noise ratio of the chromatographic peak, which also meets the requirements of UPLC, a recent replacement of HPLC [17]. ESI as an ionization source can be affected by signal suppression or enhancement, but this can be improved, at least partially, by appropriate sample preparation (cleanup), sample dilution, matrix-matched calibration, and isotope dilution mass spectrometry techniques [17].

A cleanup process is important to improve the selectivity and matrix effects by removing interference from the complex food matrices [18]. In this regard, the application of IAC in mycotoxin analysis has been a widely used method in recent years, and a fast, easy, inexpensive, effective, robust and safe (QuEChERS) strategy is also used because of its high selectivity and ability to reduce matrix effects [19]. Recently, multifunctional IACs have been used for the simultaneous analysis of AFs, OTA, ZEN, T-2/HT-2, DON, and FBs. These multifunctional IACs are commonly used to determine biomarkers of exposure to mycotoxins [20-22]. Most studies of food matrixes have been conducted on corn, cereal, and their products, and analyses of 11-14 mycotoxins have been reported [11,23-26]. Some methods require two time-consuming steps to extract mycotoxins from samples [23,25]. Another method uses water to elute mycotoxins from IACs, but this requires longer procedure times because of the need to evaporate the water under a stream of $\mathrm{N}_{2}$. These procedures are also laborious [24].

Therefore, the objective of the present study was to optimize and validate an efficient LC-MS/MS-based method with multifunctional IAC cleanup that can simultaneously determine 20 mycotoxins. The validated method was then to be applied to analyze multiple mycotoxins in samples of commercial and homemade doenjang. 


\section{Results and Discussion}

\subsection{Optimization of LC-MS/MS Parameters}

Among the 20 tested mycotoxins, the analysis of 17 was optimized in the positive ESI mode and three in negative mode based on the signal intensity of the precursor ion. Most mycotoxins were ionized in the positive mode in the form of $[\mathrm{M}+\mathrm{H}]^{+}$ions. Some of the ZEN metabolites showed higher intensities as $\left[\mathrm{M}+\mathrm{H}-\mathrm{H}_{2} \mathrm{O}\right]^{+}$. The responses of $[\mathrm{M}+\mathrm{Na}]^{+}$ions generated from T-2 and HT-2 toxins were higher than those of the other molecular forms, and this result is consistent with previous studies [27-29]. Nivalenol (NIV), DON, and 3-acetyl deoxynivalenol (3ADON) were optimized as the formic acid adduct $\left[\mathrm{M}+\mathrm{HCOO}^{-}\right]^{-}$in negative ionization mode. For two product ions of each mycotoxin, a quantifier and qualifier were selected based on the signal intensity. The optimized parameters are tabulated in Table 1, and the LC-MS/MS chromatograms of the analytes are shown in Figure 1.

Table 1. Optimized LC-MS/MS parameters.

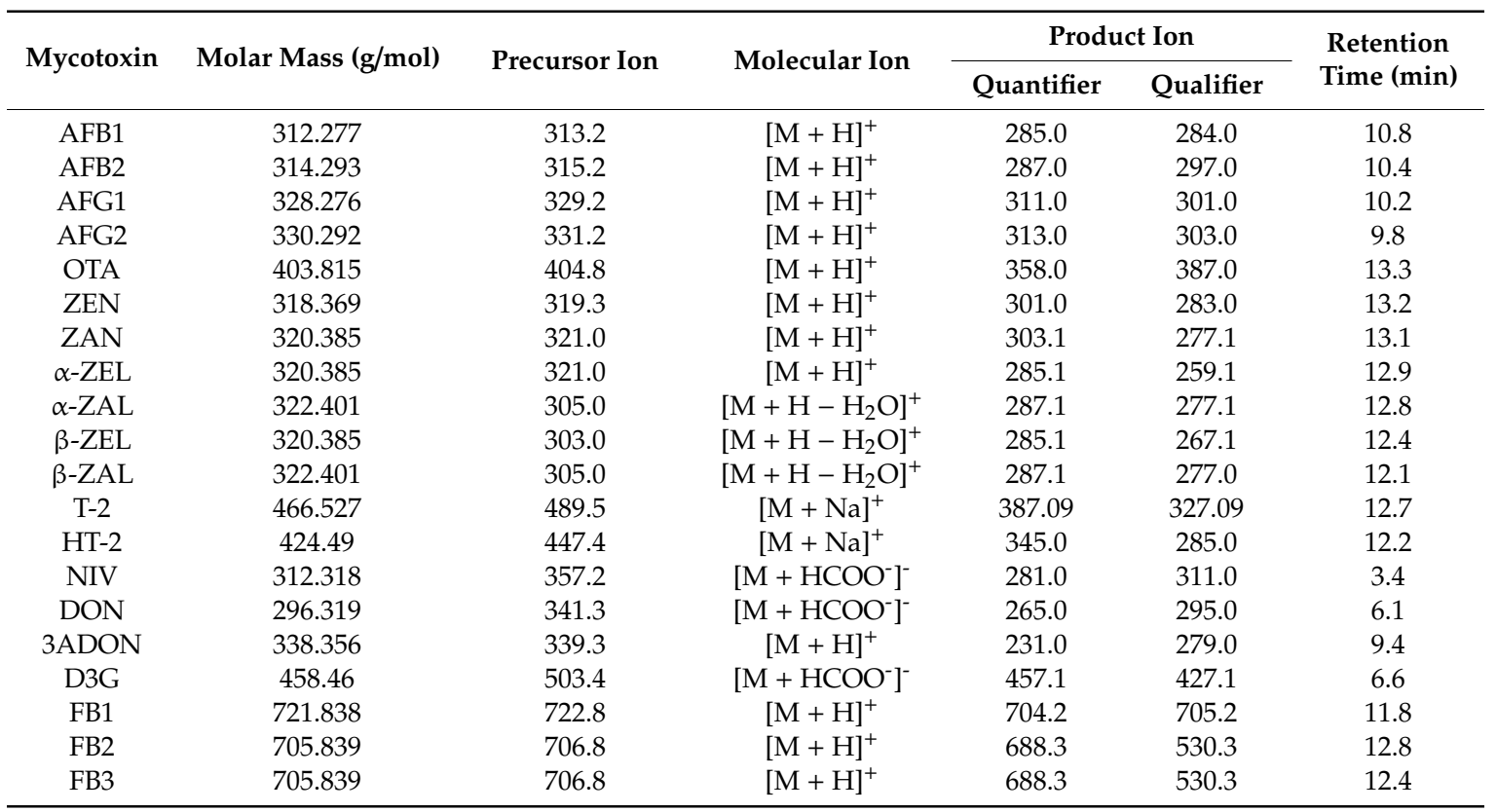




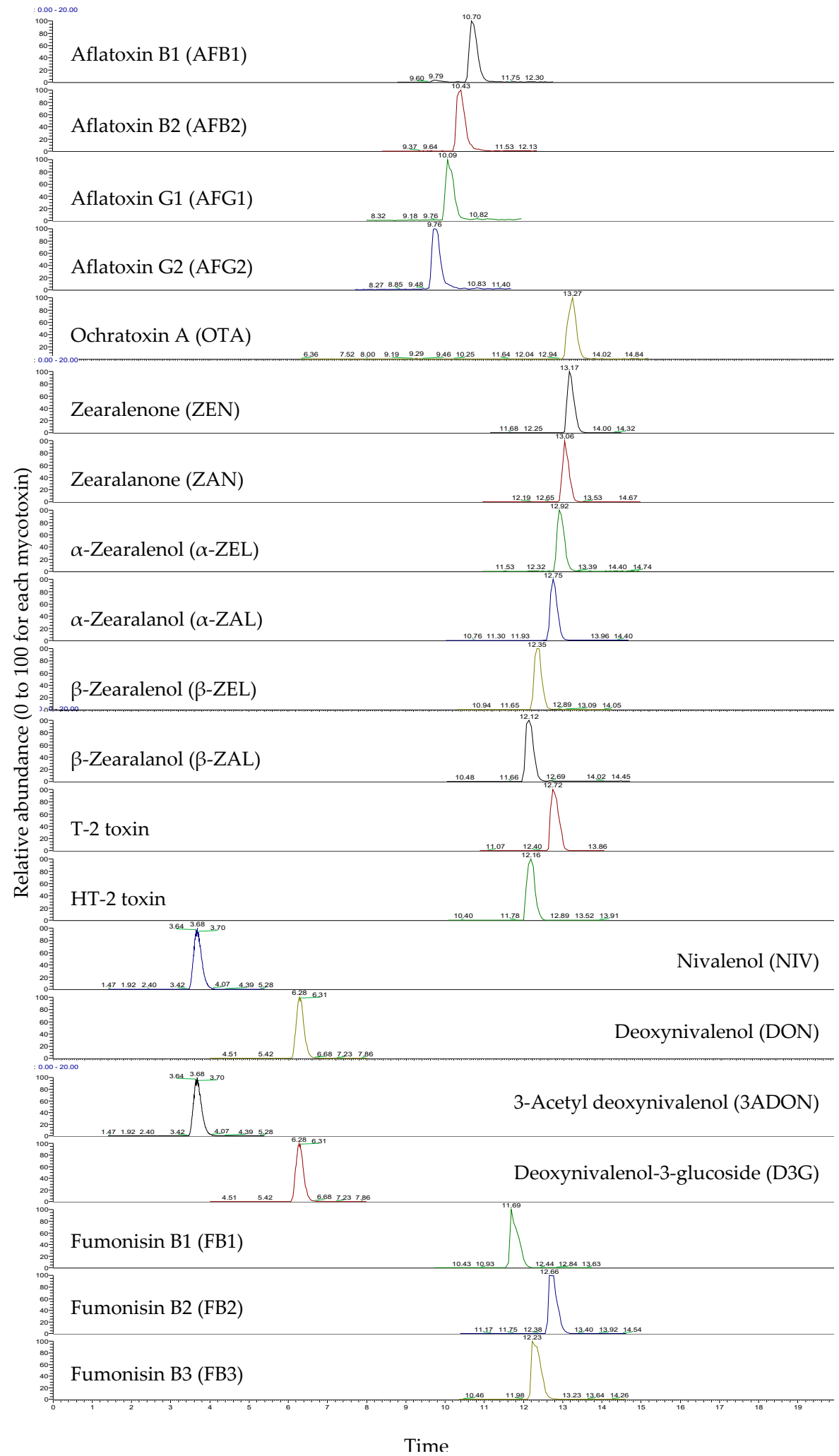

Figure 1. LC-MS/MS Chromatograms of the mycotoxin analytes. Concentrations were as follows: $20 \mu \mathrm{g} / \mathrm{kg}$ for AFB1, AFB2, AFG1, AFG2, and OTA, and $1000 \mu \mathrm{g} / \mathrm{kg}$ for ZEN, ZAN, $\alpha-Z E L, \alpha-Z A L$, $\beta$-ZEL, $\beta$-ZAL, T-2, HT-2, NIV, DON, 3ADON, D3G, FB1, FB2, and FB3. 


\subsection{Optimization of Sample Preparation Method}

Twenty-three mycotoxins (AFB1, AFB2, AFG1, AFG2, sterigmatocystin (STG), OTA, ochratoxin B (OTB), ZEN, zearalanone (ZAN), $\alpha$-zearalenol $(\alpha$-ZEL), $\alpha$-zearalanol $(\alpha$-ZAL), $\beta$-zearalenol ( $\beta$-ZEL), $\beta$-zearalanol ( $\beta$-ZAL), T-2, HT-2, NIV, DON, 3ADON, 15-acetyl deoxynivalenol (15ADON), deoxynivalenol-3-glucoside (D3G), FB1, FB2, and FB3) that might cross-react with antibodies used for the IAC were tested. A recovery test was conducted by spiking a blank doenjang sample with each mycotoxin at $10 \mu \mathrm{g} / \mathrm{kg}$ for AFs and OTA, and $100 \mu \mathrm{g} / \mathrm{kg}$ for other mycotoxins. Furthermore, SSE (\%) was determined to consider co-extraction of the analyte/matrix combination. The effects of the various cleanup methods on recoveries and matrix effects are shown in Figure 2.

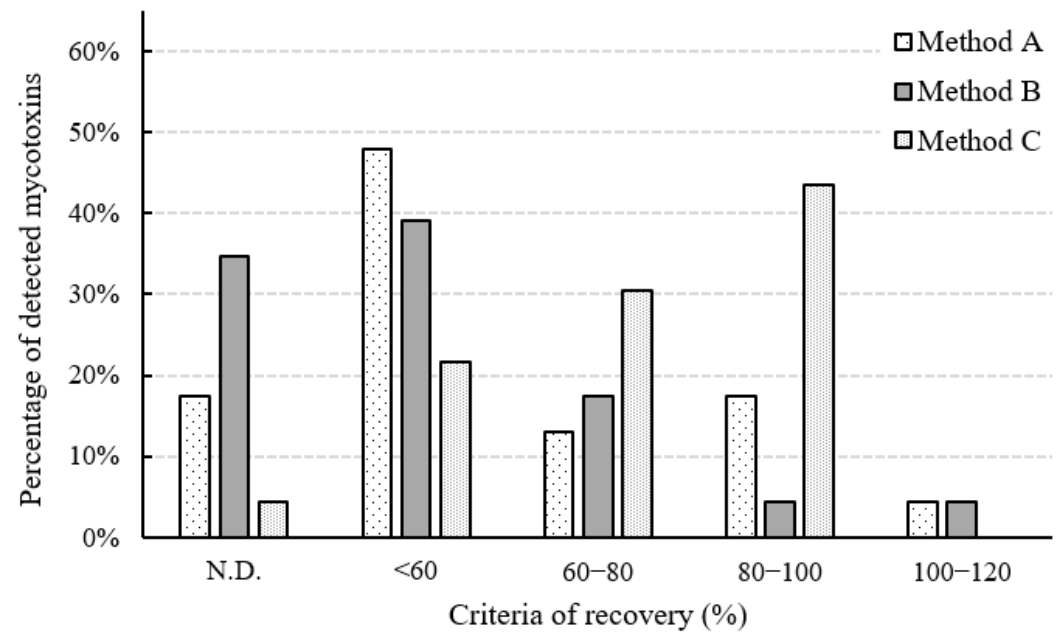

A

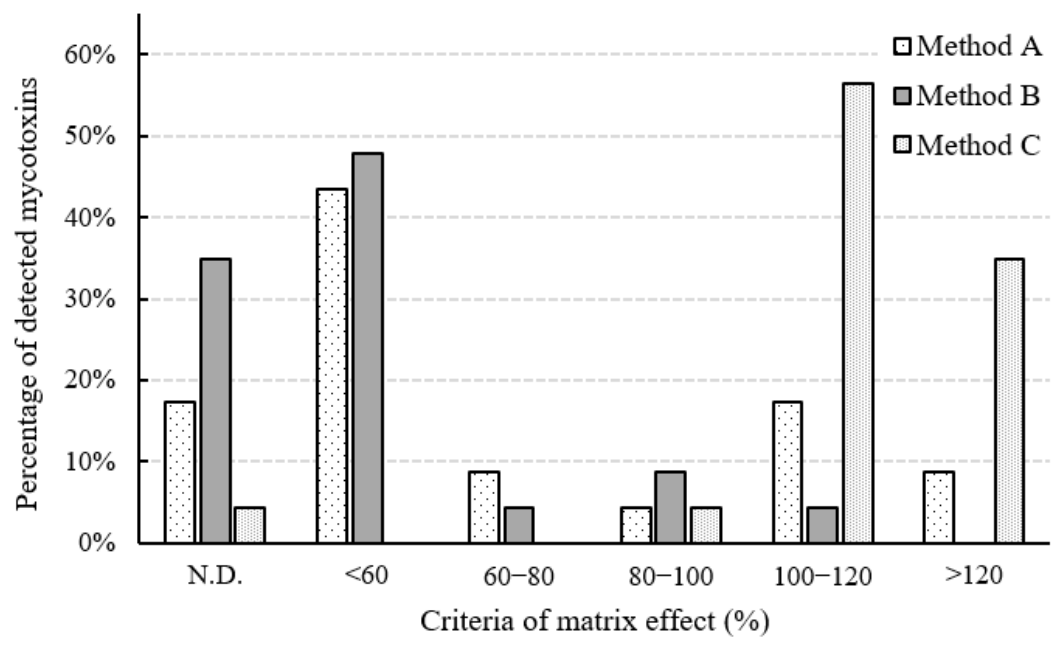

B

Figure 2. Effects of the various cleanup methods on recoveries (A) and matrix effects (B).

\subsubsection{SPE Method (Method A)}

Using method $\mathrm{A}$, an Isolute Myco column was able to purify the following 19 mycotoxins from the doenjang matrix: AFB1, AFB2, AFG2, STG, OTA, OTB, ZEN, ZAN, $\alpha$-ZEL, $\alpha$-ZAL, $\beta$-ZEL, $\beta$-ZAL, T-2 toxin, HT-2 toxin, 3ADON, D3G, FB1, FB2, and FB3. The Isolute Myco column was not suitable for the analysis of type B trichothecenes (NIV, DON, 3ADON, 15ADON, and D3G); recoveries were poor, ranging from N.D. to $10.2 \%$. On the other hand, method A yielded successful recoveries of FBs, ranging from $90.4 \%$ to $100.7 \%$. In general, an SSE (\%) of $80-120 \%$ is considered acceptable. Values outside this range indicate a strong matrix effect $[30,31]$. In terms of this SSE range, more than half of the tested analytes were highly suppressed (SSE $<80 \%$ ), while $21.7 \%$ of the mycotoxins were not suppressed or enhanced using this method. 


\subsubsection{QuEChERS (Method B)}

Method B was able to analyze the following 15 mycotoxins: STG, OTB, ZEN, ZAN, $\alpha$-ZEL, $\beta$-ZEL, T-2, HT-2, NIV, DON, 3ADON, D3G, FB1, FB2, and FB3. Method B showed satisfactory recoveries of type A trichothecenes (T-2 and HT-2), ranging from $78.3 \%$ to $82.6 \%$. However, the AFs and OTA peak responses could not be detected because of interference peaks. The QuEChERS sorbents did not effectively remove pigments and debris such as protein from the matrix. Method B also showed signal suppression (SSE $<80 \%$ ) of more than half of the mycotoxins. Only $13 \%$ of the analytes were not affected by the matrix.

\subsubsection{IAC Cleanup (Method C)}

The IAC showed cross-reactivity with 22 mycotoxins. OTB did not cross-react with antibodies in the column. STG and 15ADON showed recoveries of $<40 \%$ because they had less cross-reactivity with the antibodies in the IAC. FBs, which are the most water-soluble compounds, showed lower recoveries $(<60 \%)$ than the other mycotoxins. Method C afforded a $60-120 \%$ recovery of all mycotoxins, except for STG, OTB, 15ADON, and FBs. Of the tested mycotoxins, $60.9 \%$ were not affected by the matrix. Furthermore, matrix-induced signal enhancement was observed in $34.8 \%$ of the analytes. Among them, FBs were the most enhanced, with \%SSE ranging from $144.3 \%$ to $172.5 \%$.

Method C was better overall in terms of compounds interfering with chromatographic peaks, recovery, precision, and the number of purified mycotoxins. Therefore, further optimization using the IAC method for the simultaneous determination of mycotoxins was conducted, but excluding STG, OTB, and 15ADON, which had no or weak cross-reactions with antibodies in the IAC.

The optimized method here was as follows. In the extraction step, $\mathrm{NaCl}(1 \mathrm{~g})$ was added to reduce the interference from polar compounds in the food matrix and prevent the formation of an emulsion. In this study, the two-stage extraction procedure using water $(40 \mathrm{~mL})$ and subsequent $\mathrm{MeOH}(60 \mathrm{~mL})$ was found to be efficient because the 20 mycotoxins considered here had a wide range of polarities $(\log \mathrm{P}$ values ranging from -0.81 to 3.66). After the extraction and subsequent evaporation of the organic solvent phase, the loading of the resulting extract onto the IAC without filtration was time consuming; a significant amount of debris remained in the extract. Therefore, before loading onto the IAC, the extract was diluted four-fold with PBS, filtered through a Whatman GF/A filter to eliminate debris, and then loaded onto the column. The washing step was first carried out with $10 \mathrm{~mL}$ of water. However, this resulted in 20.5-26.5\% loss of FBs, which are water soluble analytes (data not shown). Accordingly, the washing volume was reduced from $10 \mathrm{~mL}$ to $4 \mathrm{~mL}$ to minimize the loss of FBs in the washing step. The elution of analytes from the IAC with a mixture of $\mathrm{MeOH}$ and water is time consuming because water is slow to evaporate under $\mathrm{N}_{2}$. Therefore, water as the elution solvent was replaced with $\mathrm{MeOH}$ containing $0.2 \%$ formic acid. In the subsequent procedure, $\mathrm{MeOH}$ containing $0.2 \%$ formic acid was used, which increased the elution efficiency of the FBs.

\subsection{Method Validation}

\subsubsection{Linearity, LOD, LOQ, and Matrix Effect}

Linearity was evaluated by the coefficient of determination $\left(R^{2}\right)$ of the matrix-matched external calibration curve, although $R^{2}$ is an indicator of goodness-of-fit rather than linearity. The calibration curves of six points in the ranges $0.5-20 \mu \mathrm{g} / \mathrm{kg}$ (for AFs and OTA) and $25-1000 \mu \mathrm{g} / \mathrm{kg}$ (for other mycotoxins) showed excellent linearities $\left(R^{2}>0.9994\right)$. The LOD and LOQ were calculated as $0.06-4.68 \mu \mathrm{g} / \mathrm{kg}$ and $0.17-14.18 \mu \mathrm{g} / \mathrm{kg}$, respectively (Table 2). These values are lower than those of other reported LC-MS/MS methods for multiple mycotoxins in various matrices [32-34].

The matrix effect can cause signal suppression or enhancement of the analytes and affect the ion intensity, related to recovery and repeatability. The SSE effects of all mycotoxins were in the range $86.5-103.8 \%$ (Table 2). Matrix effects were improved to within an acceptable range through the optimized method C. 
Table 2. Calibration curve, linearity, LOD, LOQ, and \%SSE of the optimized method.

\begin{tabular}{|c|c|c|c|c|c|c|c|}
\hline \multirow[b]{2}{*}{ Mycotoxin } & \multicolumn{3}{|c|}{ Calibration Curve } & \multirow[b]{2}{*}{$R^{2}$} & \multirow{2}{*}{$\begin{array}{c}\text { LOD } \\
(\mu \mathrm{g} / \mathrm{kg})\end{array}$} & \multirow{2}{*}{$\begin{array}{c}\text { LOQ } \\
(\mu \mathrm{g} / \mathrm{kg})\end{array}$} & \multirow[b]{2}{*}{ SSE (\%) } \\
\hline & $\begin{array}{c}\text { Calibration } \\
\text { Range }(\mu \mathrm{g} / \mathrm{kg})\end{array}$ & Slope & Intercept & & & & \\
\hline AFB1 & $0.5-20$ & $10,644.3$ & -142.4 & 0.9999 & 0.08 & 0.26 & 89.7 \\
\hline AFB2 & $0.5-20$ & 8025.6 & -834.4 & 0.9998 & 0.14 & 0.43 & 94.6 \\
\hline AFG1 & $0.5-20$ & 8873.9 & 394.8 & 0.9999 & 0.10 & 0.30 & 100.8 \\
\hline AFG2 & $0.5-20$ & 6878.5 & -722.1 & 0.9999 & 0.15 & 0.45 & 98.7 \\
\hline OTA & $0.5-20$ & $20,887.2$ & 8984.6 & 0.9998 & 0.06 & 0.17 & 87.0 \\
\hline ZEN & $25-1000$ & 4638.2 & -5420.4 & 0.9999 & 4.68 & 14.18 & 96.7 \\
\hline ZAN & 25-1000 & $11,972.7$ & -8964.7 & 1.0000 & 1.66 & 5.03 & 95.5 \\
\hline$\alpha-Z E L$ & $25-1000$ & 700.0 & -716.6 & 0.9999 & 1.47 & 4.44 & 94.2 \\
\hline$\alpha-Z A L$ & 25-1000 & 2098.0 & 2773.7 & 0.9998 & 2.29 & 6.94 & 95.9 \\
\hline$\beta-Z E L$ & $25-1000$ & 3649.0 & $-12,582.2$ & 1.0000 & 1.72 & 5.23 & 99.5 \\
\hline$\beta-Z A L$ & $25-1000$ & 2042.0 & 8338.2 & 0.9997 & 2.13 & 6.45 & 101.9 \\
\hline $\mathrm{T}-2$ & $25-1000$ & $23,047.8$ & $411,783.3$ & 0.9995 & 2.55 & 7.73 & 103.8 \\
\hline HT-2 & $25-1000$ & $18,293.4$ & $257,935.3$ & 0.9994 & 1.86 & 5.65 & 93.1 \\
\hline NIV & $25-1000$ & 1423.3 & -6891.8 & 0.9999 & 3.21 & 9.74 & 98.2 \\
\hline DON & $25-1000$ & 941.3 & -3171.0 & 1.0000 & 4.37 & 13.24 & 98.0 \\
\hline $3 \mathrm{ADON}$ & $25-1000$ & 821.9 & -5844.9 & 0.9999 & 0.9 & 2.73 & 100.4 \\
\hline D3G & $25-1000$ & 6246.2 & $-12,849.3$ & 0.9999 & 2.72 & 8.24 & 100.3 \\
\hline FB1 & $25-1000$ & $22,786.0$ & $-127,037.2$ & 0.9998 & 2.57 & 7.78 & 98.1 \\
\hline FB2 & $25-1000$ & $24,992.8$ & $-211,390.0$ & 1.0000 & 2.16 & 6.56 & 87.1 \\
\hline FB3 & $25-1000$ & $19,609.8$ & $-21,763.0$ & 1.0000 & 2.22 & 6.72 & 86.5 \\
\hline
\end{tabular}

\subsubsection{Recovery, Precision, and Trueness}

The mycotoxins were classified into two groups based on the similarity of their LOQ levels. Group 1 included AFs and OTA; their spiking levels were $1 \mu \mathrm{g} / \mathrm{kg}(2 \times \mathrm{LOQ}), 2 \mu \mathrm{g} / \mathrm{kg}(5 \times \mathrm{LOQ})$, $3 \mu \mathrm{g} / \mathrm{kg}(10 \times \mathrm{LOQ})$, and $6 \mu \mathrm{g} / \mathrm{kg}(20 \times \mathrm{LOQ})$. Group 2 included other mycotoxins besides AFs and OTA; their spiking levels were $15 \mu \mathrm{g} / \mathrm{kg}(2 \times \mathrm{LOQ}), 37 \mu \mathrm{g} / \mathrm{kg}(5 \times \mathrm{LOQ}), 74 \mu \mathrm{g} / \mathrm{kg}(10 \times \mathrm{LOQ})$, and $148 \mu \mathrm{g} / \mathrm{kg}$ $(20 \times \mathrm{LOQ})$. Each value was rounded to the first decimal place. The intra- and inter-day validation results are tabulated in Table 3. The mean accuracies for each mycotoxin were $96.2 \%$ for AFs, $78.8 \%$ for OTA, $88.7 \%$ for ZEN and ZEN metabolites, $83.5 \%$ for T-2 and HT-2, 94.1\% for type B trichothecenes (NIV, DON, 3ADON, and D3G), and 91.3\% for FBs. All tested recovery and precision values for AFB1, AFB2, AFG1, AFG2, OTA, DON, ZEN, T-2, HT-2, FB1, and FB2 were acceptable within the guidelines of the Commission Regulation (EU) No. 519/2014 [35]. The trueness for OTA was calculated as $-0.01 \%$, which is acceptable according to the guidelines presented by the European Commission Decision 2002/657/EC: a range of $-20 \%$ to $+10 \%$, if the mass fraction is $10 \mu \mathrm{g} / \mathrm{kg}$ [36].

The recovery and precision of this method are similar to, or better than, the previously reported LC-MS/MS methods for multiple mycotoxins in various food matrices $[26,37,38]$.

\subsubsection{Measurement Uncertainty}

The expanded uncertainty was calculated for each mycotoxin at $2 \times, 5 \times, 10 \times$, and $20 \times$ LOQ spiking levels. The mean uncertainties were $15.9 \%$ for AFs, $35.6 \%$ for OTA, $19.7 \%$ for ZEN and ZEN metabolites, $21.4 \%$ for T-2 and HT-2, 11.7\% for type B trichothecenes, and $12.2 \%$ for FBs (Table 4). The EC guidelines suggest that if the sample concentration is $<100 \mu \mathrm{g} / \mathrm{kg}$, then the acceptable expanded uncertainty is within $44 \%$, and if the concentration is $>100 \mu \mathrm{g} / \mathrm{kg}$ and $<1000 \mu \mathrm{g} / \mathrm{kg}$, then the acceptable expanded uncertainty is within $32 \%$ [39]. The uncertainties at $2 \times, 5 \times, 10 \times$, and $20 \times$ LOQ of all the mycotoxins are acceptable according to the criteria within the EU guidelines. 
Table 3. Validation parameters: intra-/inter-day recovery and precision.

\begin{tabular}{|c|c|c|c|c|c|c|c|c|c|c|c|c|c|c|c|c|}
\hline \multirow{4}{*}{$\begin{array}{c}\text { Mycotoxin } \\
\text { AFB1 }\end{array}$} & \multicolumn{16}{|c|}{ \%Recovery (\%RSD) } \\
\hline & \multicolumn{8}{|c|}{ Intra-Day $(n=9)$} & \multicolumn{8}{|c|}{ Inter-Day $(n=9)$} \\
\hline & \multicolumn{2}{|c|}{$2 \times \mathrm{LOQ}^{*}$} & \multicolumn{2}{|c|}{$5 \times \mathrm{LOQ}$} & \multicolumn{2}{|c|}{$10 \times$ LOQ } & \multicolumn{2}{|c|}{$20 \times$ LOQ } & \multicolumn{2}{|c|}{$2 \times \mathrm{LOQ}$} & \multicolumn{2}{|c|}{$5 \times$ LOQ } & \multicolumn{2}{|c|}{$10 \times$ LOQ } & \multicolumn{2}{|c|}{$20 \times$ LOQ } \\
\hline & 98.4 & $(5.9)$ & 97.8 & $(2.7)$ & 97.5 & $(4.3)$ & 101.5 & $(3.1)$ & 96.5 & (9.1) & 93.2 & $(4.8)$ & 94.7 & $(4.9)$ & 97.8 & (5.6) \\
\hline AFB2 & 100.5 & $(4.7)$ & 97.0 & (3.9) & 99.1 & $(2.2)$ & 101.1 & $(2.3)$ & 100.6 & (3.0) & 95.8 & (2.8) & 97.6 & $(3.7)$ & 99.1 & (3.8) \\
\hline AFG1 & 100.0 & $(4.0)$ & 95.6 & (3.9) & 95.4 & $(2.8)$ & 95.7 & $(2.8)$ & 94.7 & (5.3) & 94.7 & (4.3) & 93.0 & $(5.1)$ & 93.0 & $(5.2)$ \\
\hline AFG2 & 96.6 & $(2.2)$ & 94.0 & (2.0) & 95.1 & $(2.2)$ & 96.3 & $(4.4)$ & 95.7 & (6.4) & 92.3 & (5.5) & 93.4 & $(5.3)$ & 89.6 & $(9.2)$ \\
\hline OTA & 80.9 & $(7.2)$ & 76.1 & (5.3) & 83.0 & $(6.5)$ & 79.9 & (6.1) & 86.0 & (5.0) & 71.7 & (2.7) & 76.9 & $(6.4)$ & 74.6 & (3.3) \\
\hline ZEN & 89.4 & $(3.6)$ & 85.7 & (5.0) & 83.1 & (7.3) & 84.1 & (5.1) & 90.8 & (5.4) & 83.3 & (5.1) & 83.8 & $(8.7)$ & 85.2 & (6.5) \\
\hline ZAN & 99.3 & $(2.2)$ & 85.0 & (3.1) & 79.3 & $(6.8)$ & 77.6 & (4.8) & 100.2 & (2.2) & 85.1 & (3.7) & 80.3 & $(6.8)$ & 80.0 & (4.8) \\
\hline$\alpha-Z E L$ & 104.5 & $(3.3)$ & 93.4 & (5.0) & 88.6 & $(6.2)$ & 85.1 & (4.6) & 103.6 & $(4.0)$ & 92.0 & (4.5) & 87.9 & $(9.1)$ & 86.7 & (5.8) \\
\hline$\alpha-\mathrm{ZAL}$ & 89.4 & $(8.2)$ & 85.8 & (11.3) & 88.0 & $(6.1)$ & 90.8 & (4.2) & 88.0 & (7.5) & 85.7 & (8.1) & 87.0 & $(8.7)$ & 90.8 & (6.3) \\
\hline$\beta$-ZEL & 105.6 & $(3.2)$ & 89.4 & (3.9) & 83.5 & $(7.4)$ & 82.0 & (4.0) & 109.6 & (3.1) & 91.0 & (3.3) & 85.0 & (7.3) & 84.1 & (3.6) \\
\hline$\beta-Z A L$ & 92.7 & $(5.0)$ & 90.1 & (4.8) & 87.9 & $(6.6)$ & 90.2 & (4.5) & 93.6 & (5.3) & 90.5 & (5.8) & 89.7 & $(6.5)$ & 91.6 & (4.4) \\
\hline $\mathrm{T}-2$ & 75.7 & (16.2) & 92.0 & (10.4) & 96.0 & (12.6) & 94.7 & (12.6) & 75.0 & (4.5) & 91.9 & (6.0) & 96.4 & $(8.2)$ & 97.6 & (6.6) \\
\hline HT-2 & 79.2 & (5.3) & 74.3 & (13.7) & 76.6 & (12.5) & 83.0 & (11.5) & 86.8 & (5.8) & 72.6 & (13.2) & 78.9 & (12.7) & 82.1 & (15.2) \\
\hline NIV & 95.2 & (15.2) & 89.5 & $(7.4)$ & 89.5 & (12.6) & 84.3 & $(8.9)$ & 112.3 & (5.9) & 97.1 & $(7.6)$ & 86.7 & (13.4) & 85.5 & (8.1) \\
\hline $\mathrm{DON}$ & 100.3 & $(6.6)$ & 94.9 & (6.3) & 95.5 & $(8.2)$ & 89.7 & $(6.6)$ & 109.0 & (6.4) & 100.1 & (6.5) & 90.6 & $(9.7)$ & 89.6 & (5.1) \\
\hline $3 \mathrm{ADON}$ & 103.2 & $(4.0)$ & 91.5 & (6.3) & 90.5 & $(7.4)$ & 87.0 & $(10.0)$ & 107.2 & (1.8) & 95.1 & (4.9) & 96.1 & (3.8) & 93.6 & (5.1) \\
\hline D3G & 95.2 & (11.7) & 93.2 & (5.2) & 93.2 & (13.0) & 85.8 & $(8.8)$ & 106.4 & (6.4) & 95.8 & (5.1) & 88.1 & (13.0) & 85.3 & (8.0) \\
\hline FB1 & 94.3 & (11.0) & 99.5 & (8.0) & 95.1 & $(5.1)$ & 83.8 & $(6.7)$ & 93.2 & $(8.2)$ & 103.5 & $(7.4)$ & 92.3 & (13.2) & 90.3 & (7.9) \\
\hline FB2 & 100.3 & $(4.7)$ & 87.6 & $(11.5)$ & 89.1 & $(6.9)$ & 81.1 & $(9.6)$ & 103.5 & (13.5) & 88.9 & (11.8) & 86.5 & $(12.8)$ & 84.8 & $(10.0)$ \\
\hline FB3 & 96.6 & $(4.1)$ & 87.0 & $(11.2)$ & 91.2 & $(6.8)$ & 82.2 & (5.8) & 97.6 & (11.7) & 88.6 & $(9.4)$ & 88.8 & (12.9) & 84.2 & (10.3) \\
\hline
\end{tabular}

* AFs and OTA: $1 \mu \mathrm{g} / \mathrm{kg}(2 \times \mathrm{LOQ}), 2 \mu \mathrm{g} / \mathrm{kg}(5 \times \mathrm{LOQ}), 3 \mu \mathrm{g} / \mathrm{kg}(10 \times \mathrm{LOQ}), 6 \mu \mathrm{g} / \mathrm{kg}(20 \times \mathrm{LOQ}) ;$ other mycotoxins: $15 \mu \mathrm{gg} / \mathrm{kg}(2 \times \mathrm{LOQ}), 37 \mu \mathrm{g} / \mathrm{kg}(5 \times \mathrm{LOQ}), 74 \mu \mathrm{g} / \mathrm{kg}(10 \times \mathrm{LOQ}), 148 \mu \mathrm{g} / \mathrm{kg}$ $(20 \times$ LOQ) 
Table 4. Expanded uncertainty of each mycotoxin.

\begin{tabular}{|c|c|c|c|c|c|c|c|}
\hline Mycotoxin & $\begin{array}{c}\text { Spiking Level } \\
(\mu \mathrm{g} / \mathrm{kg})\end{array}$ & $\begin{array}{c}\text { Expanded } \\
\text { Uncertainty }\end{array}$ & $\begin{array}{c}\text { Uncertainty/Result } \\
(\%)\end{array}$ & Mycotoxin & $\begin{array}{c}\text { Spiking Level } \\
(\mu \mathrm{g} / \mathrm{kg})\end{array}$ & $\begin{array}{l}\text { Expanded } \\
\text { Uncertainty }\end{array}$ & $\begin{array}{c}\text { Uncertainty/Result } \\
(\%)\end{array}$ \\
\hline \multirow{4}{*}{ AFB1 } & 1 & 0.23 & 22.7 & \multirow{4}{*}{$\beta-Z A L$} & 15 & 1.18 & 15.8 \\
\hline & 2 & 0.31 & 15.4 & & 37 & 3.28 & 17.7 \\
\hline & 3 & 0.73 & 14.6 & & 74 & 7.53 & 20.3 \\
\hline & 6 & 1.26 & 12.6 & & 148 & 12.93 & 17.5 \\
\hline \multirow{4}{*}{ AFB2 } & 1 & 0.20 & 19.8 & \multirow{4}{*}{$\mathrm{T}-2$} & 15 & 2.38 & 31.7 \\
\hline & 2 & 0.31 & 15.3 & & 37 & 2.40 & 13.0 \\
\hline & 3 & 0.69 & 13.8 & & 74 & 2.92 & 7.9 \\
\hline & 6 & 1.32 & 13.2 & & 148 & 6.02 & 8.1 \\
\hline \multirow{4}{*}{ AFG1 } & 1 & 0.20 & 20.3 & \multirow{4}{*}{ HT-2 } & 15 & 2.86 & 19.1 \\
\hline & 2 & 0.31 & 15.5 & & 37 & 7.23 & 39.1 \\
\hline & 3 & 0.72 & 14.4 & & 74 & 9.85 & 26.6 \\
\hline & 6 & 1.39 & 13.9 & & 148 & 18.92 & 25.6 \\
\hline \multirow{4}{*}{ AFG2 } & 1 & 0.20 & 19.6 & \multirow{4}{*}{ NIV } & 15 & 1.10 & 14.7 \\
\hline & 2 & 0.32 & 15.8 & & 37 & 1.76 & 9.5 \\
\hline & 3 & 0.72 & 14.3 & & 74 & 4.33 & 11.7 \\
\hline & 6 & 1.35 & 13.5 & & 148 & 11.86 & 16.0 \\
\hline \multirow{4}{*}{ OTA } & 1 & 0.41 & 41.3 & \multirow{4}{*}{ DON } & 15 & 0.69 & 9.2 \\
\hline & 2 & 0.83 & 41.6 & & 37 & 1.89 & 10.2 \\
\hline & 3 & 1.42 & 28.4 & & 74 & 3.88 & 10.5 \\
\hline & 6 & 3.11 & 31.1 & & 148 & 10.49 & 14.2 \\
\hline \multirow{4}{*}{ ZEN } & 15 & 2.02 & 13.4 & \multirow{4}{*}{$3 \mathrm{ADON}$} & 15 & 0.85 & 11.4 \\
\hline & 37 & 7.21 & 19.5 & & 37 & 2.18 & 11.8 \\
\hline & 74 & 16.66 & 22.5 & & 74 & 4.30 & 11.6 \\
\hline & 148 & 29.22 & 19.7 & & 148 & 10.16 & 13.7 \\
\hline \multirow{4}{*}{ ZAN } & 15 & 1.95 & 13.0 & \multirow{4}{*}{ D3G } & 15 & 0.78 & 10.3 \\
\hline & 37 & 8.56 & 23.1 & & 37 & 1.50 & 8.1 \\
\hline & 74 & 22.02 & 29.8 & & 74 & 3.09 & 8.3 \\
\hline & 148 & 47.40 & 32.0 & & 148 & 11.45 & 15.5 \\
\hline
\end{tabular}


Table 4. Cont.

\begin{tabular}{|c|c|c|c|c|c|c|c|}
\hline Mycotoxin & $\begin{array}{c}\text { Spiking Level } \\
(\mu \mathrm{g} / \mathrm{kg})\end{array}$ & $\begin{array}{c}\text { Expanded } \\
\text { Uncertainty }\end{array}$ & $\begin{array}{c}\text { Uncertainty/Result } \\
(\%)\end{array}$ & Mycotoxin & $\begin{array}{c}\text { Spiking Level } \\
(\mu \mathrm{g} / \mathrm{kg})\end{array}$ & $\begin{array}{l}\text { Expanded } \\
\text { Uncertainty }\end{array}$ & $\begin{array}{c}\text { Uncertainty/Result } \\
(\%)\end{array}$ \\
\hline \multirow{4}{*}{$\alpha-Z E L$} & 15 & 2.01 & 13.4 & \multirow{4}{*}{ FB1 } & 15 & 1.00 & 6.7 \\
\hline & 37 & 5.84 & 15.8 & & 37 & 1.22 & 6.6 \\
\hline & 74 & 14.41 & 19.5 & & 74 & 2.40 & 6.5 \\
\hline & 148 & 33.21 & 22.4 & & 148 & 10.74 & 14.5 \\
\hline \multirow{4}{*}{$\alpha-\mathrm{ZAL}$} & 15 & 2.66 & 17.8 & \multirow{4}{*}{ FB2 } & 15 & 0.50 & 6.7 \\
\hline & 37 & 7.80 & 21.1 & & 37 & 2.86 & 15.4 \\
\hline & 74 & 14.86 & 20.1 & & 74 & 4.80 & 13.0 \\
\hline & 148 & 25.70 & 17.4 & & 148 & 17.58 & 23.8 \\
\hline \multirow{4}{*}{$\beta-Z E L$} & 15 & 2.25 & 15.0 & \multirow{4}{*}{ FB3 } & 15 & 0.53 & 7.0 \\
\hline & 37 & 6.57 & 17.7 & & 37 & 2.77 & 15.0 \\
\hline & 74 & 17.36 & 23.5 & & 74 & 3.28 & 8.9 \\
\hline & 148 & 38.32 & 25.9 & & 148 & 16.22 & 21.9 \\
\hline
\end{tabular}


The contributions of each of the factors to the total uncertainty are shown in Figure S1. The most significant contribution to the total uncertainty was from the matrix (recovery and precision of the method), except for AFs, ZAN, $\alpha$-ZEL, $\beta$-ZEL, and $\beta$-ZAL, which were most influenced by the standard preparation. Uncertainties from the standard preparation of AFs were evaluated to be relatively high because the accuracies were close to $100 \%$; thus, the uncertainties from the matrix were low. Furthermore, ZEN derivatives were prepared using neat chemicals to obtain standard solutions. Therefore, the uncertainties from the standard preparation of ZEN derivatives included additional uncertainties from apparatus used: the balance and pipette.

\subsection{Application to Actual Samples}

A total of 60 samples of commercial $(n=30)$ and homemade $(n=30)$ doenjang were analyzed using the optimized method. At least one mycotoxin contaminated $81.7 \%(49 / 60)$ of the samples. The overall results of the mycotoxin contamination levels are summarized in Table 5.

The most frequently contaminating mycotoxins in both commercial and homemade doenjang were FB1 and FB2, followed by OTA, AFB1, ZEN, and FB3. The mycotoxins with the lowest incidence were T-2 and 3ADON (not detected in all samples). Of the 60 samples, $35.0 \%(21 / 60)$ were contaminated with at least one AF within the range $0.11-5.43 \mu \mathrm{g} / \mathrm{kg}, 38.3 \%(23 / 60)$ contained OTA within the range $0.16-23.27 \mu \mathrm{g} / \mathrm{kg}, 53.3 \%$ (32/60) contained ZEN and its derivatives within the range 4.67-95.08 $\mu \mathrm{g} / \mathrm{kg}$, $20.0 \%(12 / 60)$ contained trichothecenes within the range $1.69-26.52 \mu \mathrm{g} / \mathrm{kg}$, and $50.0 \%(30 / 60)$ contained at least one FB within the range $2.48-68.52 \mu \mathrm{g} / \mathrm{kg}$. The OTA level $(23.27 \mu \mathrm{g} / \mathrm{kg})$ of one commercial product from the traditional market exceeded the regulatory limit of the Korean Government $(>20 \mu \mathrm{g} / \mathrm{kg}$ not permitted). The contamination frequency of FBs was high, but the contamination level was low, and a greater diversity of mycotoxins was detected in homemade doenjang than in commercial products. This is probably because of the variety of raw materials used in the manufacture of homemade products, and thus, the origins of mycotoxins also varied. Furthermore, some mycotoxins occurred at a higher frequency or level in homemade doenjang than in commercial products.

To determine the differences in contamination levels between commercial and homemade doenjang, a Student's $t$-test was performed $(p<0.05$ and $p<0.01)$. The contamination levels of AFB1, AFG1, ZEN, ZAN, $\beta$-ZEL, FB1, and FB2 were significantly higher in homemade doenjang compared with commercial products. This result is similar to previous findings, namely that AF is present at higher levels in homemade doenjang than in commercial samples [4,6-10]. Interestingly, 63.3\% (38/60) of the samples were cocontaminated with at least two mycotoxins. The percentage of samples cocontaminated with mycotoxins in commercial and homemade doenjang is presented in Figure 3. The commercial doenjang was contaminated with up to six mycotoxins, but the contamination levels were low: $0.27 \mu \mathrm{g} / \mathrm{kg}$ AFB1, $7.67 \mu \mathrm{g} / \mathrm{kg}$ NIV, $4.78 \mu \mathrm{g} / \mathrm{kg}$ DON, $4.05 \mu \mathrm{g} / \mathrm{kg}$ FB1, $5.78 \mu \mathrm{g} / \mathrm{kg}$ FB2, and $6.10 \mu \mathrm{g} / \mathrm{kg}$ FB3. In homemade doenjang, two samples were contaminated with nine mycotoxins. One sample was contaminated with $2.27 \mu \mathrm{g} / \mathrm{kg}$ AFB1, $0.96 \mu \mathrm{g} / \mathrm{kg}$ AFB2, $0.57 \mu \mathrm{g} / \mathrm{kg}$ AFG1, $3.99 \mu \mathrm{g} / \mathrm{kg}$ OTA, $38.10 \mu \mathrm{g} / \mathrm{kg}$ ZEN, $7.18 \mu \mathrm{g} / \mathrm{kg} \alpha-Z A L, 25.70 \mu \mathrm{g} / \mathrm{kg} \beta-Z A L, 5.52 \mu \mathrm{g} / \mathrm{kg}$ FB1, and $6.71 \mu \mathrm{g} / \mathrm{kg}$ FB2, and the other sample was contaminated with $0.34 \mu \mathrm{g} / \mathrm{kg}$ AFB1, $19.68 \mu \mathrm{g} / \mathrm{kg}$ OTA, $75.63 \mu \mathrm{g} / \mathrm{kg}$ ZEN, $7.11 \mu \mathrm{g} / \mathrm{kg}$ ZAN, $4.96 \mu \mathrm{g} / \mathrm{kg} \alpha-Z A L, 7.38 \mu \mathrm{g} / \mathrm{kg} \beta-Z E L, 11.34 \mu \mathrm{g} / \mathrm{kg}$ FB1, $6.80 \mu \mathrm{g} / \mathrm{kg}$ FB2, and $2.90 \mu \mathrm{g} / \mathrm{kg}$ FB3. The number of contaminating mycotoxins in homemade doenjang was higher than that in commercial doenjang. 
Table 5. Application to commercial and homemade doenjang samples.

\begin{tabular}{|c|c|c|c|c|c|c|c|c|}
\hline \multirow{2}{*}{ Mycotoxin } & \multicolumn{4}{|c|}{ Commercial doenjang $(\mu \mathrm{g} / \mathrm{kg}), n=30$} & \multicolumn{4}{|c|}{ Homemade doenjang $(\mu \mathrm{g} / \mathrm{kg}), n=30$} \\
\hline & Incidence $^{\mathrm{a}}$ & Mean (Positive Mean) & Median & Range & Incidence $^{a}$ & Mean (Positive Mean) & Median & Range \\
\hline AFB1* & $5 / 30$ & $0.07(0.40)$ & 0.33 & $0.11-0.96$ & $11 / 30$ & $0.54(1.48)$ & 0.65 & $0.19-4.45$ \\
\hline AFB2 & $3 / 30$ & $0.08(0.77)$ & 0.77 & $0.70-0.84$ & $5 / 30$ & $0.14(0.82)$ & 0.87 & $0.62-0.98$ \\
\hline AFG1* & $0 / 30$ & $-b$ & - & - & $5 / 30$ & $0.10(0.60)$ & 0.57 & $0.49-0.77$ \\
\hline AFG2 & $0 / 30$ & - & - & - & $2 / 30$ & $0.03(0.47)$ & 0.47 & $0.21-0.73$ \\
\hline OTA & $5 / 30$ & $0.80(4.80)$ & 0.19 & $0.16-23.27$ & $18 / 30$ & $3.05(5.08)$ & 3.78 & $0.20-19.68$ \\
\hline $\mathrm{ZEN}^{* *}$ & $4 / 30$ & $2.79(20.90)$ & 17.47 & $5.16-43.48$ & $17 / 30$ & $17.82(31.45)$ & 19.40 & $5.86-85.50$ \\
\hline ZAN * & $0 / 30$ & - & - & - & $5 / 30$ & $0.94(5.67)$ & 6.18 & $3.28-7.11$ \\
\hline$\alpha-Z E L$ & $0 / 30$ & - & - & - & $1 / 30$ & $0.28(8.29)$ & 8.29 & 8.29 \\
\hline$\alpha-Z A L$ & $2 / 30$ & $0.34(5.17)$ & 5.17 & $5.13-5.21$ & $6 / 30$ & $1.04(5.21)$ & 5.01 & $4.05-7.18$ \\
\hline$\beta-Z E L$ * & $0 / 30$ & - & - & - & $5 / 30$ & $1.56(9.39)$ & 9.91 & $7.38-11.56$ \\
\hline$\beta-Z A L$ & $5 / 30$ & $0.93(5.56)$ & 5.64 & $4.67-6.19$ & $3 / 30$ & $1.66(16.56)$ & 15.59 & $8.40-25.70$ \\
\hline $\mathrm{T}-2$ & $0 / 30$ & - & - & - & $0 / 30$ & - & - & - \\
\hline HT-2 & $1 / 30$ & $0.88(26.52)$ & 26.52 & 26.52 & $1 / 30$ & $0.06(1.69)$ & 1.69 & 1.69 \\
\hline NIV & $1 / 30$ & $0.26(7.67)$ & 7.67 & 7.67 & $6 / 30$ & $0.89(4.43)$ & 4.31 & $3.27-6.03$ \\
\hline $\mathrm{DON}$ & $4 / 30$ & $1.72(12.88)$ & 14.25 & $4.78-18.25$ & $1 / 30$ & $0.51(15.35)$ & 15.35 & 15.35 \\
\hline $3 \mathrm{ADON}$ & $0 / 30$ & - & - & - & $0 / 30$ & - & - & - \\
\hline D3G & $0 / 30$ & - & - & - & $1 / 30$ & $0.09(2.72)$ & 2.72 & 2.72 \\
\hline $\mathrm{FB} 1 * *$ & $8 / 30$ & $1.50(5.61)$ & 6.64 & $2.21-8.13$ & $16 / 30$ & $5.04(9.44)$ & 9.39 & $5.52-17.26$ \\
\hline $\mathrm{FB} 2$ * & $8 / 30$ & $1.57(5.90)$ & 6.20 & $1.85-9.11$ & $16 / 30$ & $7.00(13.33)$ & 6.03 & $3.86-56.19$ \\
\hline FB3 & $9 / 30$ & $1.68(5.60)$ & 6.10 & $2.48-9.22$ & $12 / 30$ & $2.00(5.00)$ & 4.96 & $2.37-9.36$ \\
\hline
\end{tabular}

a: number of positive samples/total number of samples; ${ }^{\text {b }}$ : not detected $(<\mathrm{LOD})$; difference between commercial and homemade products $\left({ }^{*} p<0.05\right)$; difference between commercial and homemade products $(* * p<0.01)$ 

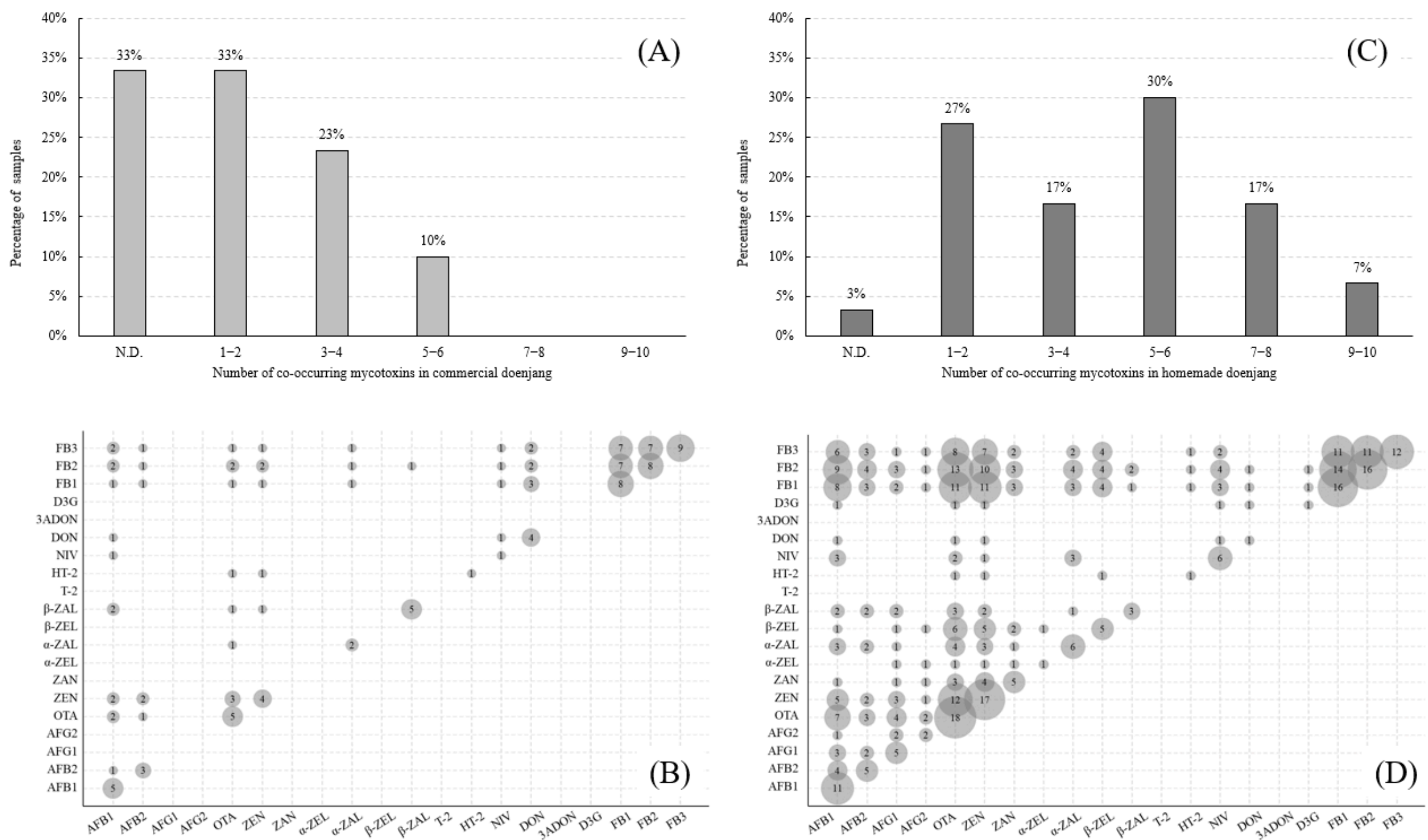

Figure 3. Co-occurrence and prevalence of mycotoxins in commercial $(\mathbf{A}, \mathbf{B})$ and homemade $(\mathbf{C}, \mathbf{D})$ doenjang. 
The co-occurrence between mycotoxins is summarized in Figure 3. The co-occurrence of the fumonisin B series occurred the most frequently in commercial doenjang, and OTA-ZEN and DON-FB1 were the second most frequently co-occurring mycotoxins. In homemade doenjang, the co-occurrence of FB1-FB2, OTA-FB2, and OTA-ZEN was frequently observed. In particular, 40\% (2/5) of AFB1-positive commercial samples and 64\% (11/17) of AFB1-positive homemade samples were cocontaminated with OTA, and $60 \%$ (3/5) of OTA-positive commercial samples and 67\% (12/18) of OTA-positive homemade samples were cocontaminated with ZEN. Greater cocontamination of mycotoxins occurred in the homemade doenjang than in the commercial doenjang.

This difference is attributed to the different production processes of commercial and homemade doenjang. Commercial products are fermented by artificial inoculation using a specific strain (e.g., Aspergillus oryzae or Aspergillus sojae), but homemade doenjang is naturally fermented with ambient microorganisms [40]. Thus, the homemade process is vulnerable to contamination by mycotoxigenic fungi.

In conclusion, an efficient LC-MS/MS-based method with multifunctional IAC cleanup was successfully developed, and validated, for the simultaneous determination of 20 mycotoxins. This method can be applied to other fermented soybean foods with similar matrices, such as Japanese miso, Indonesian tempeh, and Chinese sufu (furu). Furthermore, to the best of our knowledge, this study is the first attempt to simultaneously determine up to 20 mycotoxins after sample cleanup using multifunctional IACs in soybean fermented foods. In the doenjang samples collected in this study (a rather limited number of samples), $81.7 \%$ of the samples were contaminated with at least one mycotoxin and $1.7 \%$ exceeded the present regulatory limits for OTA. It is recommended that further monitoring with a larger number of samples be conducted for the sake of public safety regarding mycotoxins in doenjang.

\section{Materials and Methods}

\subsection{Chemicals and Reagents}

Certified mycotoxin standards of AFB1, AFB2, AFG1, AFG2, STG, OTA, OTB, ZEN, T-2, HT-2, NIV, DON, 3ADON), 15ADON, and D3G were purchased from Romer Labs (Union, MO) and dissolved in acetonitrile (ACN). Certified standard solutions of FB1, FB2, and FB3 in ACN/water (50:50, v/v) were also purchased from Romer Labs. ZEN metabolites (ZAN, $\alpha$-ZEL, $\alpha$-ZAL, $\beta$-ZEL, and $\beta$-ZAL) were obtained from Sigma-Aldrich (St. Louis, MO) and prepared in ACN. FB1, FB2, and FB3 were stored at $4{ }^{\circ} \mathrm{C}$. Other standard solutions were stored at $-20{ }^{\circ} \mathrm{C}$. A certified reference material (CRM) of doenjang powder for OTA $(49.50 \pm 1.17 \mu \mathrm{g} / \mathrm{kg})$ was purchased from the Korea Research Institute of Standards and Science (KRISS) and used for the trueness test.

\subsection{Sampling}

We collected 60 samples (30 commercial and 30 homemade) of doenjang in 2018-2019. Commercial doenjang samples were purchased from online retailers, supermarkets, and local markets. Homemade doenjang samples were collected from four areas in Korea (Gyeonggi, Chungcheong, Jeolla, and Gyeongsang) using the snowball method, which is a nonprobability sampling technique in which existing study subjects recruit future subjects from among their acquaintances [41]. Collected samples were stored at $4{ }^{\circ} \mathrm{C}$ and then equilibrated at room temperature prior to analysis.

\subsection{Sample Preparation}

\subsubsection{Method A}

In the solid phase extraction (SPE) method (Method A), an Isolute (Myco, $3 \mathrm{~mL}, 60 \mathrm{mg}$ ) column (Biotage, Sweden) was selected for use, because it employs a simple SPE procedure to bind mycotoxins of interest selectively to the sorbent. Sample preparation was conducted according to a multimycotoxin 
analysis method for vegetable raw materials and their processed products, as specified by the Korean Food Code (2018) and operator's application note, with some modifications [42]. Briefly, $5 \mathrm{~g}$ of sample was extracted with $20 \mathrm{~mL}$ of $50 \%$ ACN (0.1\% formic acid, v/v) by shaking for $30 \mathrm{~min}$, followed by centrifugation of the extract at $5000 \times g$ for $10 \mathrm{~min}$. The supernatant was filtered through a Whatman GF/B filter, and $3 \mathrm{~mL}$ of the filtrate was diluted with $12 \mathrm{~mL}$ of water. The Isolute columns were conditioned with $2 \mathrm{~mL}$ of ACN, followed by $2 \mathrm{~mL}$ of water. Diluted supernatant $(5 \mathrm{~mL})$ was loaded onto the column, which was then washed with $2 \mathrm{~mL}$ of water, followed by $2 \mathrm{~mL}$ of $10 \% \mathrm{ACN}(v / v)$. Air was passed through the column for a few seconds. Analytes were eluted with $2 \mathrm{~mL}$ of $\mathrm{ACN}$ $(0.1 \%$ formic acid, $v / v)$ and $4 \mathrm{~mL}$ of $\mathrm{MeOH}$. The eluate was evaporated under $\mathrm{N}_{2}$ at $50{ }^{\circ} \mathrm{C}$, and the residue was reconstituted with $50 \% \mathrm{MeOH}(0.1 \%$ formic acid, v/v).

\subsubsection{Method B}

Sample preparation with a QuEChERS kit (containing $4 \mathrm{~g}$ of hydrous magnesium sulfate and $1 \mathrm{~g}$ of sodium chloride with ceramic homogenizer; Agilent Technologies, Palo Alto, CA) was conducted according to the Agilent application note and the method reported by Andrade et al., with some modifications [43]. The sample ( $2 \mathrm{~g})$ was weighed into a $50 \mathrm{~mL}$ conical tube, water $(10 \mathrm{~mL})$ was added, the mixture was held for $5 \mathrm{~min}$, and then $10 \mathrm{~mL}$ of $\mathrm{ACN}(2 \%$ formic acid, $v / v)$ was added. The mixture was shaken for $20 \mathrm{~min}$ at $300 \mathrm{rpm}$, and then QuEChERS salt $\left(4 \mathrm{~g} \mathrm{MgSO}_{4}, 1 \mathrm{~g} \mathrm{NaCl}\right)$ was added. Next, ceramic homogenizer was added, and the mixture was shaken manually for 3 min. The extract was then centrifuged at $5000 \times g$ for $5 \mathrm{~min}$. The supernatant was filtered through Whatman No. 4 filter paper. The filtrate $(5 \mathrm{~mL})$ was dried under a stream of $\mathrm{N}_{2}$ at $50{ }^{\circ} \mathrm{C}$ and then reconstituted with $50 \% \mathrm{MeOH}$.

\subsubsection{Method C}

Samples were prepared using a Myco 6-in-1 IAC from Vicam (Milford, MA) according to the manufacturer's protocol, with some modifications. The sample (10 g) was weighed into a high-form beaker, water $(40 \mathrm{~mL})$ was added, and the mixture was homogenized for $2 \mathrm{~min}$ at $5000 \mathrm{rpm}$ (T25 Digital Ultra-Turrax; IKA-Werke, Staufen, Germany). Without removing the first extract, MeOH (60 mL) was added to the beaker, and the mixture was homogenized again for $2 \mathrm{~min}$ (5000 rpm). The extract was filtered through Whatman No. 4 filter paper. The filtrate $(5 \mathrm{~mL})$ was evaporated to approximately $2 \mathrm{~mL}$, and then PBS (5 mL) was added. The extract/PBS mixture $(7 \mathrm{~mL})$ was loaded onto an IAC, which was washed with water $(10 \mathrm{~mL})$. The column was dried by passing air through for a few seconds. $\mathrm{MeOH}(1.5 \mathrm{~mL})$ was applied to the column and eluted into a test tube, a second portion of $\mathrm{MeOH}$ $(1.5 \mathrm{~mL})$ was applied, and the bottom of the IAC was closed. After $5 \mathrm{~min}$, the eluate was allowed to flow again. We passed $2 \mathrm{~mL}$ of water through the column into the same test tube. Subsequently, the column was dried by passing air through it for a few seconds. The eluent was evaporated under a stream of $\mathrm{N}_{2}$ at $40{ }^{\circ} \mathrm{C}$ and the residue was reconstituted in $50 \% \mathrm{MeOH}(0.2 \mathrm{~mL}, \mathrm{v} / \mathrm{v})$.

Finally, method C (with an IAC) was selected for further optimization because of its potential to clean up and analyze mycotoxins in a doenjang matrix simultaneously. The optimized method comprised the following steps. A total of $10 \mathrm{~g}$ of sample was extracted with $1 \mathrm{~g}$ of sodium chloride. The extraction and filtration steps were as described above. Filtered extract $(4 \mathrm{~mL})$ was diluted with $16 \mathrm{~mL}$ of PBS and then filtered, once again, through a Whatman GF/A filter. A $20 \mathrm{~mL}$ volume of the GF/A filtrate was loaded onto an IAC, followed by washing of the column with $4 \mathrm{~mL}$ of water. The mycotoxins were eluted from the IAC using $2 \mathrm{~mL}$ of $\mathrm{MeOH}$ containing $0.2 \%$ formic acid (v/v) and a further $3 \mathrm{~mL}$ of $\mathrm{MeOH}$ containing $0.2 \%$ formic acid $(v / v)$. The bottom of the IAC was closed. The column was held closed for $5 \mathrm{~min}$ and the eluate was allowed to flow. The final residue was reconstituted in $0.5 \mathrm{~mL}$ of $50 \% \mathrm{MeOH}(v / v)$. 


\subsection{LC-MS/MS Conditions}

Detection and quantification were performed using a Thermo Accela UHPLC system (Thermo Fisher Scientific, San Jose, CA) coupled with a Velos Pro mass spectrometer (Thermo Fisher Scientific, Waltham, MA) equipped with positive and negative ESI modes. Analysis was conducted with a Waters Xbridge $C_{18}$ column $(2.1 \mathrm{~mm} \times 100 \mathrm{~mm}, 3.4 \mu \mathrm{m}$; Waters, Milford, MA). Separation was conducted over a period of $20 \mathrm{~min}$ using a flow rate of $0.2 \mathrm{~mL} / \mathrm{min}$ : $90 \%$ solvent $\mathrm{A}(0.1 \%$ formic acid in water), $10 \%$ solvent $\mathrm{B}(0.1 \%$ formic acid in $\mathrm{MeOH})$ for $3 \mathrm{~min}$ to reach equilibrium. Solvent $\mathrm{A}$ was first applied in a linear gradient elution system from $90 \%$ to $5 \%$ within 13 min and then held to $16 \mathrm{~min}$. Solvent A was then changed $90 \%$ to $16.1 \mathrm{~min}$ and the column was re-equilibrated to $20 \mathrm{~min}$. The column was equilibrated for $3 \mathrm{~min}$ prior to each analysis. The column oven temperature was held at $35{ }^{\circ} \mathrm{C}$. The collision-induced dissociation energy was $35 \%$. Helium was used as the collision gas. Spray voltages were 5.0 and $-5.0 \mathrm{kV}$ for the positive and negative modes, respectively. Source heater and capillary temperatures were set at $250{ }^{\circ} \mathrm{C}$ and $275{ }^{\circ} \mathrm{C}$, respectively. Sheath gas, auxiliary gas, and sweep gas $\left(\mathrm{N}_{2}\right)$ were set at 35,5 , and 5 arbitrary units, respectively. The $\mathrm{m} / \mathrm{z}$ range of 50-2000 was fully scanned. Data analysis was performed using Thermo Xcalibur Qual Browser 2.0 software.

\subsection{Method Validation}

Standard curves of each mycotoxin were evaluated by the coefficient of determination $\left(R^{2}\right)$ of six-point matrix-matched calibration curves that were constructed by plotting the peak area (signal intensity). The limit of detection (LOD) and limit of quantification (LOQ) were determined using the slope of the calibration curve (S) and the standard deviation (SD) of the area from the lowest concentration in the calibration curve. LOD and LOQ were calculated from the following equations: $\mathrm{LOD}=3.3 \times \mathrm{SD} / \mathrm{S}$ and $\mathrm{LOQ}=10 \times \mathrm{SD} / \mathrm{S}$. The recovery was represented by recovery experiments according to the following equation: analyzed concentration of spiked samples calculated from matrix-matched standard/spiking concentration $\times 100$. Precision was calculated as the relative standard deviation of the replicated recovery experiments. The intra- and inter-day recovery and precision were measured at spiking levels of $2 \times, 5 \times, 10 \times$, and $20 \times$ LOQ concentrations.

A blank doenjang sample free from 20 mycotoxins was spiked with each mycotoxin before sample pretreatment. To evaluate the trueness of the method, a CRM of doenjang powder for OTA $(49.5 \pm 1.17 \mu \mathrm{g} / \mathrm{kg})$ from the KRISS was used. The trueness was calculated by dividing the concentration determined by the certified value and multiplying by 100 in consideration of recovery.

To calculate the matrix effects, six concentrations of each mycotoxin standard were added to both the blank matrix after sample preparation and the reference solvent $(50 \% \mathrm{MeOH}, v / v)$. These two sets of solutions were directly injected to the LC-MS/MS system, 10 times each. Signal suppression or enhancement (SSE) was calculated using the following equation: (slope of the matrix-matched calibration curve/slope of the solvent-based calibration curve) $\times 100$.

The measurement uncertainty was quantified according to the EURACHEM/Cooperation on International Traceability in Analytical Chemistry (CITAC) Guide-Quantifying Uncertainty in Analytical Measurement (2012) [44]. Balances, volumetric measuring devices, reference materials, linear calibration curve interpolation, and instrumental factors were considered sources of uncertainty. Combined standard uncertainty was calculated as the positive square root of the total variance obtained by combining all the uncertainty components. The expanded measurement of uncertainty was calculated using a standard coverage factor of two for an approximate confidence level of $95 \%$.

Supplementary Materials: The following are available online at http://www.mdpi.com/2072-6651/11/10/594/s1, Figure S1: Contributions of each of the factors to the total uncertainty (10 $\mu \mathrm{g} / \mathrm{kg}$ for AFs and OTA, $15 \mu \mathrm{g} / \mathrm{kg}$ for other mycotoxins).

Author Contributions: Conceptualization, S.Y.W., F.T. and H.S.C.; Methodology, S.Y.W. and S.Y.L.; Formal Analysis and Investigation, S.Y.W., S.B.P., S.Y.R. and S.Y.L.; Writing-Original Draft Preparation, S.Y.W.; Writing-Review and Editing, S.Y.W., F.T. and H.S.C.; Project Administration, H.S.C. 
Funding: This research was supported by the Chung-Ang University Graduate Research Scholarship in 2018, Republic of Korea.

Acknowledgments: This Research was supported by the Chung-Ang University in Center for Biotechnology Facilities.

Conflicts of Interest: The authors declare no conflict of interest.

\section{Abbreviations}

3ADON, 3-acetyl deoxynivalenol; $15 \mathrm{ADON}$, 15-acetyl deoxynivalenol; $\mathrm{ACN}$, acetonitrile; $\mathrm{AFX}$, aflatoxin $X(X=\mathrm{B} 1$, etc.); $R^{2}$, coefficient of determination; $C R M$, certified reference material; D3G, deoxynivalenol-3-glucoside; DON, deoxynivalenol; ESI, electrospray ionization; FBX, fumonisin $X(X=B 1$, etc.); HPLC-FLD, high-performance liquid chromatography coupled with fluorescence detection; IAC, immunoaffinity column; LOD, limit of detection; LOQ, limit of quantification; NIV, nivalenol; OT(A/B), ochratoxin A/B; QqQ, triple quadrupole; QuEChERS, quick, easy, cheap, effective, rugged, and safe; SPE, solid phase extraction; SSE, signal suppression or enhancement; STG, sterigmatocystin; ZAL, zearalanol; ZEL, zearalenol; ZAN, zearalanone; ZEN, zearalenone.

\section{References}

1. Sweeney, M.J.; Dobson, A.D. Molecular biology of mycotoxin biosynthesis. FEMS Microbiol. Lett. 1999, 175, 149-163. [CrossRef] [PubMed]

2. Kabak, B.; Dobson, A.D.; Var, I. Strategies to prevent mycotoxin contamination of food and animal feed: A review. Crit. Rev. Food Sci. Nutr. 2006, 46, 593-619. [CrossRef] [PubMed]

3. Kim, J.G.; Lee, Y.W.; Bullerman, L.B. Changes of aflatoxins during the ripening and storage of Korean soy sauce and soybean paste and the characteristics of the changes. Part 3. Korean Public Health Res. 2000, 1, 21-28.

4. Ahn, S.; Lee, S.; Lee, J.; Kim, B. Accurate determination of ochratoxin A in Korean fermented soybean paste by isotope dilution-liquid chromatography tandem mass spectrometry. Food Chem. 2016, 190, 368-373. [CrossRef] [PubMed]

5. Kok, W.T. Derivatization reactions for the determination of aflatoxins by liquid chromatography with fluorescence detection. J. Chromatogr. B Biomed. Sci. Appl. 1994, 659, 127-137. [CrossRef]

6. Ok, H.E.; Kim, H.J.; Shim, W.B.; Lee, H.; Bae, D.H.; Chung, D.H.; Chun, H.S. Natural occurrence of aflatoxin B1 in marketed foods and risk estimates of dietary exposure in Koreans. J. Food. Protect. 2007, 70, 2824-2828. [CrossRef] [PubMed]

7. Park, M.J.; Yoon, M.H.; Hong, H.G.; Joe, T.S.; Lee, I.S.; Park, J.H.; Ko, H.U. A survey of the presence of aflatoxins in food. J. Food Hyg. Saf. 2008, 23, 108-112.

8. Kim, K.Y.; Nam, M.J.; Nam, B.R.; Ryu, H.J.; Song, J.E.; Shim, W.B.; Lee, S.H.; Jeong, D.H. Determination of total aflatoxins in foods by parallelism of ELISA and LC/MS/MS. JEHS 2010, 36, 52-60. [CrossRef]

9. Kim, M.; Kim, Y.S. Detection of foodborne pathogens and analysis of aflatoxin levels in home-made doenjang samples. Prev. Nutr. Food Sci. 2012, 17, 172-176. [CrossRef]

10. Park, J.W.; Yoo, M.S.; Kuk, J.H.; Ji, Y.A.; Lee, J.H. Simultaneous determination and monitoring of aflatoxin and ochratoxin A in food. J. Food Hyg. Saf. 2013, 28, 75-82. [CrossRef]

11. Kim, D.H.; Hong, S.Y.; Kang, J.; Cho, S.; Lee, K.; An, T.; Lee, C.; Chung, S. Simultaneous determination of multi-mycotoxins in cereal grains collected from South Korea by LC/MS/MS. Toxins 2017, 9, 106. [CrossRef] [PubMed]

12. Clarke, R.; Connolly, L.; Frizzell, C.; Elliott, C.T. Cytotoxic assessment of the regulated, co-existing mycotoxins aflatoxin B1, fumonisin B1 and ochratoxin, in single, binary and tertiary mixtures. Toxicon 2014, 90, 70-81. [CrossRef] [PubMed]

13. Vejdovszky, K.; Hahn, K.; Braun, D.; Warth, B.; Marko, D. Synergistic estrogenic effects of fusarium and alternaria mycotoxins in vitro. Arch. Toxicol. 2017, 91, 1447-1460. [CrossRef] [PubMed]

14. Gao, Y.; Li, S.; Bao, X.; Luo, C.; Yang, H.; Wang, J.; Zhao, S.; Zheng, N. Transcriptional and proteomic analysis revealed a synergistic effect of aflatoxin M1 and ochratoxin A mycotoxins on the intestinal epithelial integrity of differentiated human Caco-2 cells. J. Proteome Res. 2018, 17, 3128-3142. [CrossRef] [PubMed]

15. Hird, S.J.; Lau, B.P.Y.; Schuhmacher, R.; Krska, R. Liquid chromatography-mass spectrometry for the determination of chemical contaminants in food. Trends Anal. Chem. 2014, 59, 59-72. [CrossRef]

16. Eshelli, M.; Qader, M.; Jambi, E.; Hursthouse, A.; Rateb, M. Current status and future opportunities of omics tools in mycotoxin research. Toxins 2018, 10, 433. [CrossRef] [PubMed] 
17. Frenich, A.G.; Romero-González, R.; del Mar Aguilera-Luiz, M. Comprehensive analysis of toxics (pesticides, veterinary drugs and mycotoxins) in food by UHPLC-MS. Trends Anal. Chem. 2014, 63, 158-169. [CrossRef]

18. Krska, R.; Schubert-Ullrich, P.; Molinelli, A.; Sulyok, M.; MacDonald, S.; Crews, C. Mycotoxin analysis: An update. Food Addit. Contam. 2008, 25, 152-163. [CrossRef]

19. Pereira, V.; Fernandes, J.; Cunha, S. Mycotoxins in cereals and related foodstuffs: A review on occurrence and recent methods of analysis. Trends Food Sci. Technol. 2014, 36, 96-136. [CrossRef]

20. Solfrizzo, M.; Gambacorta, L.; Lattanzio, V.M.; Powers, S.; Visconti, A. Simultaneous LC-MS/MS determination of aflatoxin M1, ochratoxin A, deoxynivalenol, de-epoxydeoxynivalenol, $\alpha$ and $\beta$-zearalenols and fumonisin B1 in urine as a multi-biomarker method to assess exposure to mycotoxins. Anal. Bioanal. Chem. 2011, 401, 2831-2841. [CrossRef]

21. Gambacorta, S.; Solfrizzo, H.; Visconti, A.; Powers, S.; Cossalter, A.; Pinton, P.; Oswald, I. Validation study on urinary biomarkers of exposure for aflatoxin B1, ochratoxin A, fumonisin B1, deoxynivalenol and zearalenone in piglets. World Mycotoxin J. 2013, 6, 299-308. [CrossRef]

22. Wallin, S.; Gambacorta, L.; Kotova, N.; Lemming, E.W.; Nälsén, C.; Solfrizzo, M.; Olsen, M. Biomonitoring of concurrent mycotoxin exposure among adults in Sweden through urinary multi-biomarker analysis. Food Chem. Toxicol. 2015, 83, 133-139. [CrossRef] [PubMed]

23. Tang, Y.Y.; Lin, H.Y.; Chen, Y.C.; Su, W.T.; Wang, S.C.; Chiueh, L.C.; Shin, Y.C. Development of a quantitative multi-mycotoxin method in rice, maize, wheat and peanut using UPLC-MS/MS. Food Anal. Methods 2013, 6, 727-736. [CrossRef]

24. Lattanzio, V.M.T.; Ciasca, B.; Powers, S.; Visconti, A. Improved method for the simultaneous determination of aflatoxins, ochratoxin $\mathrm{A}$ and fusarium toxins in cereals and derived products by liquid chromatography-tandem mass spectrometry after multi-toxin immunoaffinity clean up. J. Chromatogr. A 2014, 1354, 139-143. [CrossRef] [PubMed]

25. Jung, S.Y.; Choe, B.C.; Choi, E.J.; Jeong, H.J.; Hwang, Y.S.; Shin, G.Y.; Kim, J.H. Survey of mycotoxins in commonly consumed Korean grain products using an LC-MS/MS multimycotoxin method in combination with immunoaffinity clean-up. Food Sci. Biotechnol. 2015, 24, 1193-1199. [CrossRef]

26. Park, J.H.; Kim, D.H.; Moon, J.Y.; An, J.A.; Kim, Y.W.; Chung, S.H.; Lee, C. Distribution analysis of twelve mycotoxins in corn and corn-derived products by LC-MS/MS to evaluate the carry-over ratio during wet-milling. Toxins 2018, 10, 319. [CrossRef] [PubMed]

27. Sulyok, M.; Berthiller, F.; Krska, R.; Schuhmacher, R. Development and validation of a liquid chromatography/tandem mass spectrometric method for the determination of 39 mycotoxins in wheat and maize. Rapid Commun. Mass Spectrom. 2006, 20, 2649-2659. [CrossRef] [PubMed]

28. Ren, Y.; Zhang, Y.; Shao, S.; Cai, Z.; Feng, L.; Pan, H.; Wang, Z. Simultaneous determination of multi-component mycotoxin contaminants in foods and feeds by ultra-performance liquid chromatography tandem mass spectrometry. J. Chromatogr. A 2007, 1143, 48-64. [CrossRef]

29. Soleimany, F.; Jinap, S.; Faridah, A.; Khatib, A. A UPLC-MS/MS for simultaneous determination of aflatoxins, ochratoxin A, zearalenone, DON, fumonisins, T-2 toxin and HT-2 toxin, in cereals. Food Control. 2012, 25, 647-653. [CrossRef]

30. Frenich, A.G.; Romero-González, R.; Gómez-Pérez, M.L.; Vidal, J.L. Multi-mycotoxin analysis in eggs using a QuEChERS-based extraction procedure and ultra-high-pressure liquid chromatography coupled to triple quadrupole mass spectrometry. J. Chromatogr. A 2011, 1218, 4349-4356. [CrossRef]

31. Dong, H.; Xian, Y.; Xiao, K.; Wu, Y.; Zhu, L.; He, J. Development and comparison of single-step solid phase extraction and QuEChERS clean-up for the analysis of 7 mycotoxins in fruits and vegetables during storage by UHPLC-MS/MS. Food Chem. 2019, 274, 471-479. [CrossRef] [PubMed]

32. McElhinney, C.; O'Kiely, P.; Elliott, C.; Danaher, M. Development and validation of an UHPLC-MS/MS method for the determination of mycotoxins in grass silages. Food Addit. Contam. Part A Chem. Anal. Control Expo. Risk Assess. 2015, 32, 2101-2112. [CrossRef] [PubMed]

33. Wang, M.; Jiang, N.; Xian, H.; Wei, D.; Shi, L.; Feng, X. A single-step solid phase extraction for the simultaneous determination of 8 mycotoxins in fruits by ultra-high performance liquid chromatography tandem mass spectrometry. J. Chromatogr. A 2016, 1429, 22-29. [CrossRef] [PubMed]

34. Romera, D.; Mateo, E.M.; Mateo-Castro, R.; Gómez, J.V.; Gimeno-Adelantado, J.V.; Jiménez, M. Determination of multiple mycotoxins in feedstuffs by combined use of UPLC-MS/MS and UPLC-QTOF-MS. Food Chem. 2018, 267, 140-148. [CrossRef] [PubMed] 
35. Commission Regulation (EU) No 519/2014 of 16 May 2014 amending Regulation (EC) No 401/2006 as regards methods of sampling of large lots, spices and food supplements, performance criteria for T-2, HT-2 toxin and citrinin and screening methods of analysis. Off. J. Eur. Union. 2014, 147, $29-43$.

36. Commission Decision (EC) No 2002/657 implementing Council Directive 96/23/EC concerning the performance of analytical methods and the interpretation of results. Off. J. Eur. Commun. 2002, 8, 1-29.

37. Tolosa, J.; Graziani, G.; Gaspari, A.; Chianese, D.; Ferrer, E.; Mañes, J.; Ritieni, A. Multi-mycotoxin analysis in durum wheat pasta by liquid chromatography coupled to quadrupole orbitrap mass spectrometry. Toxins 2017, 9, 59. [CrossRef]

38. Flores-Flores, M.E.; González-Peñas, E. An LC-MS/MS method for multi-mycotoxin quantification in cow milk. Food Chem. 2017, 218, 378-385. [CrossRef]

39. European Commission. Report on the Relationship between Analytical Results, Measurement Uncertainty, Recovery Factors and the Provisions of EU Food and Feed Legislation, with Particular Reference to Community Legislation Concerning. 2004, p. 8. Available online: https://ec.europa.eu/food/sites/food/files/safety/docs/cs_ contaminants_sampling_analysis-eport_2004_en.pdf (accessed on 10 October 2019).

40. Park, K.Y.; Hwang, K.M.; Jung, K.O.; Lee, K.B. Studies on the standardization of doenjang (Korean soybean paste) 1. Standardization of manufacturing method of doenjang by literatures. J. Korean Soc. Food Sci. Nutr. 2002, 31, 343-350.

41. Sharma, G. Pros and cons of different sampling techniques. Int. J. Appl. Res. 2017, 3, 749-752.

42. Korean Food Code. Standards and Specifications for Food Product; Ministry of Food and Drug Safety: Seoul, Korea, 2018.

43. Andrade, G.; Pimpinato, R.F.; Francisco, J.G.; Monteiro, S.; Calori-Domingues, M.A.; Tornisielo, V.L. Evaluation of mycotoxins and their estimated daily intake in popcorn and cornflakes using LC-MS techniques. LWT Food Sci. Technol. 2018, 95, 240-246. [CrossRef]

44. Ellison, S.; Williams, A. Eurachem/CITAC Guide. Quantifying Uncertainty in Analytical Measurement, 3rd ed.; EURACHEM/CITAC Guide CG 4: London, UK, 2012; Available online: https://www.eurachem.org/images/ stories/Guides/pdf/QUAM2012_P1.pdf (accessed on 10 October 2019).

(C) 2019 by the authors. Licensee MDPI, Basel, Switzerland. This article is an open access article distributed under the terms and conditions of the Creative Commons Attribution (CC BY) license (http://creativecommons.org/licenses/by/4.0/). 